\title{
Hypothyroidism and hyperthyroidism and breast cancer risk: a nationwide cohort study
}

\author{
Mette Søgaard' , Dóra Körmendiné Farkas' ${ }^{1}$, Vera Ehrenstein ${ }^{1}$, \\ Jens Otto Lunde Jørgensen ${ }^{2}$, Olaf M Dekkers ${ }^{1,3}$ and Henrik Toft Sørensen ${ }^{1}$ \\ Departments of ${ }^{1}$ Clinical Epidemiology, ${ }^{2}$ Endocrinology and Internal Medicine (MEA), Aarhus University Hospital, \\ Olof Palmes Allé 43-45, DK-8200 Aarhus N, Denmark and ${ }^{3}$ Departments of Endocrinology and Clinical Epidemiology, \\ Leiden University Medical Center, Leiden, The Netherlands
}

Correspondence

should be addressed

to M Søgaard

Email

mso@clin.au.dk

\begin{abstract}
Objective: The association between thyroid disease and breast cancer risk remains unclear. We, therefore examined the association between hypothyroidism, hyperthyroidism and breast cancer risk.

Design: This was a population-based cohort study.

Methods: Using nationwide registries, we identified all women in Denmark with a first-time hospital diagnosis of hypothyroidism or hyperthyroidism, 1978-2013. We estimated the excess risk of breast cancer among patients with hypothyroidism or hyperthyroidism compared with the expected risk in the general population, using standardized incidence ratios (SIRs) as a measure of risk ratio. Breast cancer diagnoses in the first 12 months following diagnosis of thyroid disease were excluded from the calculations to avoid diagnostic work-up bias.

Results: We included 61873 women diagnosed with hypothyroidism and 80343 women diagnosed with hyperthyroidism. Median follow-up time was 4.9 years (interquartile range (IQR): 1.8-9.5 years) for hypothyroidism and 7.4 years (IQR: 3.1-13.5 years) for hyperthyroidism. Hyperthyroidism was associated with a slightly increased breast cancer risk compared with the general population (SIR: 1.11, 95\% CI: 1.07-1.16), which persisted beyond 5 years of follow-up (SIR: 1.13, 95\% Cl: 1.08-1.19). In comparison, hypothyroidism was associated with a slightly lower risk of breast cancer (SIR: $0.94,95 \% \mathrm{Cl}: 0.88-1.00$ ).

Stratification by cancer stage at diagnosis, estrogen receptor status, age, comorbidity, history of alcohol-related disease and clinical diagnoses of obesity produced little change in cancer risk.

Conclusions: We found an increased risk of breast cancer in women with hyperthyroidism and a slightly decreased risk in women with hypothyroidism indicating an association between thyroid function level and breast cancer risk.
\end{abstract}

\section{Introduction}

Breast cancer is the most frequent cancer in females, with 458337 new cases diagnosed in Europe in 2012 (1). Endogenous and exogenous sex hormones play an important role in the etiology of breast cancer (2). In vitro, high levels of thyroid hormones have estrogen-like effects $(3,4)$, promoting breast cancer cell proliferation $(5,6)$ and stimulating angiogenesis (7). Therefore, hyperthyroidism, characterized by increased levels of thyroid hormones, may potentially also increase breast cancer risk.

Epidemiological evidence concerning thyroid disorders and breast cancer risk remains unclear. Some epidemiological studies have reported increased risks associated with hypothyroidism $(8,9)$, hyperthyroidism $(10,11,12)$, goiter (13) and thyroid autoimmune diseases $(14,15)$, while others have found no association $(9,16,17$, 18). Only four studies employed a cohort design $(9,11,12$, $15)$; in case-control studies, reverse causation is a plausible competing explanation since breast cancer or its treatment may affect thyroid hormone levels (19). Moreover, some studies have not distinguished between hypothyroidism and hyperthyroidism, despite their contrasting hormonal profiles $(13,16,17)$. We conducted a

Published by Bioscientifica Ltd. 
nationwide population-based cohort study in Denmark to examine the association between hypothyroidism, hyperthyroidism and risk of breast cancer.

\section{Subject and methods}

\section{Study setting}

In this nationwide population-based cohort study in Denmark we included data from 1 January 1978 to 31 November 2013. The Danish National Health Service guarantees tax-supported health care for all residents. Health service utilization is tracked by several nationwide registries, which are linkable using each resident's universal personal identifier, assigned to all Danish residents at birth or upon immigration since 1968 (20). Our study's source population consisted of the 4177429 women who resided in Denmark during the study period.

\section{Hypothyroidism and hyperthyroidism}

The Danish National Patient Registry (DNPR) contains information on all inpatient hospitalizations at Danish non-psychiatric hospitals since 1977 and outpatient and emergency department visits since 1995 (21, 22). Each hospital visit is recorded by physicians with one primary diagnosis and one or more secondary diagnoses classified according to the International Classification of Diseases, 8th edition (ICD-8) until the end of 1993, and ICD-10 thereafter. We used the DNPR to identify all women with a first-time diagnosis of hypothyroidism or hyperthyroidism from 1978 through 2013 (see Supplementary Table 1 for codes, see section on supplementary data given at the end of this article). Women with a diagnosis of hypothyroidism and hyperthyroidism on the same date $(n=481)$ were excluded, and women with hyperthyroidism who subsequently developed hypothyroidism $(n=8185)$ or vice versa $(n=1895)$ were censored on the date of the new diagnosis.

\section{Breast cancer}

To identify incident breast cancer cases, the cohorts of women with a diagnosis of hypothyroidism or hyperthyroidism were linked to the Danish Cancer Registry (DCR), which records all incident cancers in Denmark since 1943, with mandatory reporting since 1987 (23). We excluded women with a breast cancer diagnosis prior to the diagnosis of hypothyroidism or hyperthyroidism. Through the DCR, we also obtained data on breast cancer stage at diagnosis (classified according to Summary Staging as localized vs non-localized disease). We also performed a linkage to the Danish Pathology Registry (24) to retrieve data on estrogen receptor (ER) status at breast cancer diagnosis starting in 1997 (as pathology data became available in that year).

\section{Comorbid diseases}

We computed the Charlson Comorbidity Index (CCI) scores for each patient based on all available DNPR inpatient hospitalization records preceding the date of diagnosis of hypothyroidism or hyperthyroidism (25). We categorized severity of comorbidities as low (CCI score $=$ 0 ), medium (CCI score $=1-2$ ) or high (CCI score $\geq 3$ ), excluding breast cancer diagnoses from the CCI score calculation. We also used the DNPR to access information on clinical diagnoses of obesity and alcohol-related disease (see Supplementary Table 1 for codes).

\section{Statistical analysis}

We followed women from the date of their first diagnosis of hypothyroidism or hyperthyroidism until incident breast cancer, death, emigration, or 31 November 2013, whichever came first. We computed the expected number of breast cancer cases using national incidence rates by age (5-year bands) and year of diagnosis (5-year periods) multiplied by person-years of follow-up. We computed standardized incidence ratios (SIRs) for breast cancer as the ratio of observed to expected cancers. Breast cancer diagnoses in the first 12 months following diagnosis of thyroid disease were excluded from the calculations to avoid overestimating the association by including prevalent occult breast cancers diagnosed during the diagnostic work-up for thyroid disease. Confidence intervals (CIs) for the SIRs were computed assuming that the observed number of cases in a specific category followed a Poisson distribution, using Byar's approximation (26). We stratified results by age at diagnosis, calendar period, CCI score categories, hospital diagnoses of obesity and alcoholrelated disease, breast cancer stage at diagnosis and ER status (for women diagnosed between 1997 and 2013). We also computed the absolute risk of breast cancer with death as a competing risk. The follow-up period was categorized as 1-5 years and $>5$ years. As radioactive iodine (RAI) treatment may increase breast cancer risk (27), we conducted a sensitivity analysis in which followup was censored at initiation of RAI treatment. Smoking is an established risk factor for Graves' disease (28), we 
therefore also conducted a sensitivity analysis excluding patients with Graves' disease in order to reduce potential confounding by smoking. We restricted this analysis to 1994-2011, the period during which there was a specific code for Graves' disease in the Danish ICD version (see Supplementary Table 1 for codes). Finally, we conducted a sensitivity analysis restricted to women who were diagnosed with hypothyroidism or hyperthyroidism starting in 1995 or later in order to capture information on outpatient diagnoses.

The study was approved by the Danish Data Protection Agency, record number 1-16-02-1-08. Studies based on registry data in Denmark do not require informed consent.

\section{Results}

There were 61873 women diagnosed with hypothyroidism (median age at diagnosis: 71 years, interquartile range (IQR): $52-82$ years) and 80343 women diagnosed with hyperthyroidism (median age: 70 years, IQR: $55-82$ years). Median follow-up was 4.9 years (IQR: 1.8-9.8 years) for patients with hypothyroidism and 7.4 years (IQR: 3.1-13.5 years) for patients with hyperthyroidism respectively. The proportion of women diagnosed with hypothyroidism increased substantially over time. In the calendar periods when outpatient diagnoses were available, $15.0 \%$ of hypothyroidism cases were diagnosed during 1998-2002, compared with 35.2\% during 20082013 (Table 1). The corresponding percentages for hyperthyroidism were 20.4 and 20.6\%. Most patients had no comorbidity requiring hospitalization at the time of diagnosis of hypothyroidism $(65.8 \%)$ or hyperthyroidism (74.8\%). Hospital diagnoses of obesity were more prevalent among women with hypothyroidism compared with hyperthyroidism ( 8.5 vs $3.5 \%)$. Less than $2 \%$ had a diagnosis of alcohol-related disease.

Overall, hyperthyroidism was associated with an increased risk of breast cancer (SIR: 1.11, 95\% CI: 1.071.16), while hypothyroidism was associated with a slightly decreased risk of breast cancer (SIR: 0.94, 95\% CI: 0.881.00) (Table 2). The hyperthyroidism-associated increased risk persisted beyond 5 years of follow-up (SIR: 1.13, 95\% CI: 1.08-1.19). Stratification by cancer stage at diagnosis, ER status, age, comorbidity, history of alcohol-related disease and clinical diagnoses of obesity produced little change in breast cancer risk. Breast cancer risk in women with hyperthyroidism was unaffected by censoring at RAI treatment initiation (SIR: 1.08, 95\% CI: 0.98-1.18, during 2002-2013) or by exclusion of patients with Graves' disease (SIR: 1.09, 95\% CI: 1.02-1.16, during 1994-2011).
Table 1 Descriptive characteristics of women diagnosed with hypothyroidism or hyperthyroidism, Denmark, 1978-2013.

\begin{tabular}{|c|c|c|c|c|}
\hline & \multicolumn{2}{|c|}{ Hypothyroidism } & \multicolumn{2}{|c|}{ Hyperthyroidism } \\
\hline & Number & $\%$ & Number & $\%$ \\
\hline Total & 61873 & 100 & 80343 & 100 \\
\hline \multicolumn{5}{|c|}{ Age at time of diagnosis } \\
\hline$<30$ years & 5594 & 9.0 & 6655 & 8.3 \\
\hline $30-49$ years & 14546 & 23.5 & 20661 & 25.7 \\
\hline $50-69$ years & 19292 & 31.2 & 27861 & 34.7 \\
\hline$\geq 70$ years & 22441 & 36.3 & 25166 & 31.3 \\
\hline \multicolumn{5}{|c|}{ Calendar period at time of diagnosis } \\
\hline $1978-1982$ & 3,175 & 5.1 & 6599 & 8.2 \\
\hline $1983-1987$ & 3403 & 5.5 & 5605 & 7.0 \\
\hline 1988-1992 & 4431 & 7.2 & 6563 & 8.2 \\
\hline 1993-1997 & 6346 & 10.3 & 12634 & 15.7 \\
\hline 1998-2002 & 9271 & 15.0 & 16372 & 20.4 \\
\hline 2003-2007 & 13463 & 21.8 & 16059 & 20.0 \\
\hline 2008-2013 & 21784 & 35.2 & 16511 & 20.6 \\
\hline \multicolumn{5}{|c|}{ Charlson comorbidity index score } \\
\hline Low $(0)$ & 40729 & 65.8 & 60081 & 74.8 \\
\hline Moderate (1-2) & 16577 & 26.8 & 16687 & 20.8 \\
\hline $\operatorname{High}(\geq 3)$ & 4567 & 7.4 & 3575 & 4.5 \\
\hline \multicolumn{5}{|l|}{ Obesity diagnosis } \\
\hline No & 56754 & 91.7 & 77512 & 96.5 \\
\hline Yes & 5119 & 8.3 & 2831 & 3.5 \\
\hline \multicolumn{5}{|c|}{ Alcohol-related disease } \\
\hline No & 60221 & 97.3 & 79306 & 98.7 \\
\hline Yes & 1652 & 2.7 & 1037 & 1.3 \\
\hline
\end{tabular}

Between 1995 and 2013, 48363 women had a diagnosis of hypothyroidism, of which 20225 (41.8\%) were inpatient diagnoses and 28138 (58.2\%) were outpatient diagnoses. Over the same period, 56877 women had a diagnosis of hyperthyroidism. Of these women, 19532 (34.3\%) had inpatient diagnoses and 37345 (65.7\%) had outpatient diagnoses. Restricting the study period to 1995-2013 produced the same overall SIR estimates as the main analysis (Supplementary Table 2, see section on supplementary data given at the end of this article). Stratification by inpatient vs outpatient diagnoses indicated a slightly higher breast cancer risk increase associated with outpatient diagnoses (SIR: 1.17, 95\% CI: 1.06-1.29) of hyperthyroidism compared with inpatient diagnoses (SIR: 1.07, 95\% CI: 0.94-1.22), particularly after 5 years of follow-up (Supplementary Table 2).

\section{Discussion}

This nationwide population-based cohort study spanning over a 30-year period revealed an elevated risk of breast cancer in women with hyperthyroidism, which increased with longer follow-up. Over the same period, women with 
Table 2 Standardized incidence ratios for breast cancer in women with hypothyroidism and hyperthyroidism, Denmark, 1978-2013.

\begin{tabular}{|c|c|c|c|c|c|c|}
\hline & \multicolumn{3}{|c|}{ Women with hypothyroidism } & \multicolumn{3}{|c|}{ Women with hyperthyroidism } \\
\hline & $\begin{array}{c}\text { No. of } \\
\text { person-years }\end{array}$ & $\begin{array}{l}\text { Observed/ } \\
\text { expected cancer }\end{array}$ & SIR $(95 \% \mathrm{Cl})$ & $\begin{array}{c}\text { No. of } \\
\text { person-years }\end{array}$ & $\begin{array}{l}\text { Observed/ } \\
\text { expected cancer }\end{array}$ & SIR $(95 \% \mathrm{CI})$ \\
\hline Overall & 361640 & $970 / 1031$ & $0.94(0.88-1.00)$ & 674236 & $2122 / 1903$ & $1.11(1.07-1.16)$ \\
\hline \multicolumn{7}{|c|}{ Age at diagnosis of thyroid disease } \\
\hline$<30$ years & 37559 & $17 / 15$ & $1.17(0.68-1.88)$ & 72244 & $35 / 45$ & $0.78(0.54-1.08)$ \\
\hline 30-49 years & 102422 & $197 / 206$ & $0.96(0.83-1.10)$ & 229087 & $626 / 510$ & $1.23(1.13-1.33)$ \\
\hline $50-69$ years & 137188 & $486 / 505$ & $0.96(0.88-1.05)$ & 255053 & $1004 / 922$ & $1.09(1.02-1.16)$ \\
\hline$\geq 70$ years & 84472 & 270/306 & $0.88(0.78-0.99)$ & 117852 & $457 / 426$ & $1.07(0.98-1.18)$ \\
\hline \multicolumn{7}{|c|}{ Calendar period of the diagnosis of thyroid disease } \\
\hline 1978-1982 & 35984 & $95 / 95$ & $1.00(0.81-1.23)$ & 111722 & $309 / 288$ & $1.07(0.96-1.20)$ \\
\hline 1983-1987 & 3292 & $79 / 92$ & $0.85(0.68-1.06)$ & 79651 & $250 / 215$ & $1.17(1.03-1.32)$ \\
\hline 1988-1992 & 41069 & $145 / 122$ & $1.19(1.00-1.40)$ & 77714 & $249 / 220$ & $1.13(0.99-1.28)$ \\
\hline 1993-1997 & 63914 & $181 / 188$ & $0.96(0.83-1.11)$ & 139540 & $475 / 403$ & $1.18(1.08-1.29)$ \\
\hline 1998-2002 & 76474 & $194 / 223$ & $0.87(0.75-1.00)$ & 141060 & $448 / 415$ & $1.08(0.98-1.18)$ \\
\hline 2003-2007 & 76232 & $191 / 221$ & $0.87(0.75-1.00)$ & 96007 & $302 / 283$ & $1.07(0.95-1.19)$ \\
\hline 2008-2013 & 35045 & $85 / 89$ & $0.95(0.76-1.18)$ & 28542 & $89 / 79$ & $1.12(0.90-1.38)$ \\
\hline \multicolumn{7}{|c|}{ Charlson comorbidity index score } \\
\hline Low (0) & 273988 & $706 / 746$ & $0.95(0.88-1.02)$ & 573498 & $1734 / 1563$ & $1.11(1.06-1.16)$ \\
\hline Moderate (1-2) & 75678 & $217 / 242$ & $0.90(0.78-1.02)$ & 89699 & $346 / 300$ & $1.16(1.04-1.28)$ \\
\hline $\operatorname{High}(\geq 3)$ & 11974 & $47 / 42$ & $1.12(0.82-1.49)$ & 11038 & $42 / 40$ & $1.04(0.75-1.41)$ \\
\hline \multicolumn{7}{|l|}{ Obesity diagnosis } \\
\hline No & 337465 & $918 / 963$ & $0.95(0.89-1.02)$ & 659357 & 2075/1860 & $1.12(1.07-1.16)$ \\
\hline Yes & 24175 & $52 / 68$ & 0.77 (0.57-1.01) & 14878 & $47 / 44$ & $1.08(0.79-1.43)$ \\
\hline \multicolumn{7}{|c|}{ Alcohol-related disease } \\
\hline No & 354797 & 943/1010 & $0.93(0.88-1.00)$ & 668539 & 2106/1888 & $1.12(1.07-1.16)$ \\
\hline Yes & 6842 & $27 / 21$ & $1.30(0.86-1.89)$ & 5697 & $16 / 15$ & $1.05(0.60-1.71)$ \\
\hline \multicolumn{7}{|c|}{ Breast cancer stage at diagnosis } \\
\hline Localized & 361640 & $467 / 491$ & $0.95(0.87-1.04)$ & 674236 & $1012 / 909$ & $1.11(1.05-1.18)$ \\
\hline Non-localized & 361640 & $377 / 427$ & $0.88(0.80-0.98)$ & 674236 & $883 / 809$ & $1.09(1.02-1.17)$ \\
\hline Unknown stage & 361640 & $126 / 113$ & $1.11(0.93-1.32)$ & 674236 & $227 / 185$ & $1.23(1.07-1.40)$ \\
\hline \multicolumn{7}{|l|}{ ER status ${ }^{\mathrm{a}}$} \\
\hline ER negative & 200431 & $67 / 77$ & $0.87(0.67-1.10)$ & 293504 & $124 / 118$ & $1.05(0.88-1.26)$ \\
\hline ER positive & 200431 & $387 / 423$ & $0.91(0.83-1.01)$ & 293504 & $701 / 637$ & $1.10(1.02-1.19)$ \\
\hline Missing ER status & 200431 & $55 / 70$ & $0.78(0.59-1.02)$ & 293504 & $100 / 103$ & $0.97(0.79-1.18)$ \\
\hline \multicolumn{7}{|l|}{ Length of follow-up } \\
\hline $1-5$ years & 161183 & $390 / 424$ & $0.92(0.83-1.02)$ & 244231 & $661 / 615$ & $1.07(0.99-1.16)$ \\
\hline$>5$ years & 200457 & $580 / 607$ & $0.96(0.88-1.04)$ & 430005 & $1461 / 1288$ & $1.13(1.08-1.19)$ \\
\hline
\end{tabular}

aPeriod for ER status: 1997-2013.

hypothyroidism experienced a slightly decreased risk of breast cancer.

During the last 50 years, several epidemiological studies have examined the association between thyroid disorders and the risk for breast cancer. Most of the previous studies examined the effect of thyroid hormone levels on breast cancer risk in a case-control setting (14, $16,17,29)$, in which reverse causation may be difficult to rule out. Our findings are in line with three of the earlier cohort studies that found an association between higher premorbid levels of thyroid hormone and breast cancer risk $(11,12,15)$, while the fourth cohort study found an association between low levels of free thyroxine and an increased risk of breast cancer (9). The lack of increase in the risk of breast cancer in women with hypothyroidism, observed in this study, is also in agreement with the results of a recent meta-analysis of 12 observational studies showing no association between hypothyroidism and breast cancer risk (18).

Several biological processes may underlie the observed associations between thyroid diseases and breast cancer risk. In vitro studies have demonstrated a proliferative effect of triiodothyronine ( $\mathrm{T}_{3}$, the active thyroid hormone) in the breast $(5,6)$. At the cellular level, $T_{3}$ binds to highaffinity nuclear receptors and induces transcription of target genes involved in energy homeostasis and cell proliferation. In vitro studies suggest a critical role of these receptors in breast cancer development $(5,30,31)$. 
In contrast to the experimental evidence that $T_{3}$ and estrogen synergistically stimulate certain breast cancer cell lines $(3,4,6,32)$, in our study, the association between hyperthyroidism and breast cancer risk was not modified by ER status.

We conducted a large nationwide population-based cohort study, with complete follow-up and highly valid data for thyroid disease $(21,23,33)$ and breast cancer diagnoses $(34,35)$. The higher incidence of hyperthyroidism compared with hypothyroidism is in agreement with previous studies (36), as is the increased incidence of thyroid disease over time (37). One contributing factor to the higher incidence in hyperthyroidism is the fact that before 1995 only inpatient diagnosis were recorded in the DNPR (21), and hyperthyroidism is more likely than hypothyroidism to be diagnosed and treated in an inpatient setting as also shown in our study. However, a sensitivity analysis restricted to patients diagnosed from 1995 onward and stratified by inpatient vs outpatient diagnoses, yielded similar findings. A limitation of our study was the lack of laboratory data. We were therefore unable to distinguish between clinical and subclinical thyroid disease, as we were also unable to link the hormone levels at time of diagnosis to breast cancer risk. Of note, the exposure window in hyperthyroidism is short, as the hyperthyroid state is rapidly diagnosed, and ensuing treatment normalizes thyroid levels within a few weeks (38). Finally, the observed association between hyperthyroidism and breast cancer risk may have been underestimated due to incompletely ascertained (and therefore not adjusted for) lifestyle risk factors for breast cancer, such as obesity and alcohol consumption, both of which are associated with a reduced risk of hyperthyroidism $(28,39)$ but an increased risk of breast cancer (40). We stratified our analyses by hospital diagnoses of obesity and alcohol-related illness, however, these diagnoses are likely to capture only the most severe cases. Smoking has been associated with an increased risk of Graves' disease (28), but has no consistent association with breast cancer risk (41), and exclusion of patients with Graves' disease did not change our estimates. Finally, we did not address the role of hormonal treatment in the observed association. The role of treatment should be explored in further studies.

In conclusion, we found an increased risk of breast cancer in women with hyperthyroidism and a slightly decreased risk in women with hypothyroidism suggesting an association between the thyroid function level and breast cancer risk.

\section{Supplementary data}

This is linked to the online version of the paper at http://dx.doi.org/10.1530/ EJE-15-0989.

\section{Declaration of interest}

The authors report no conflict of interest that could be perceived as prejudicing the impartiality of the research reported.

\section{Funding}

This work was supported by the Program for Clinical Research Infrastructure (PROCRIN), established by the Lundbeck and the Novo Nordisk Foundations; by the Danish Cancer Society (R73-A4284-13-S17); and by the Aarhus University Research Foundation.

\section{References}

1 European Cancer Observatory, International Agency for Research on Cancer. Available at http://eco.iarc.fr. Accessed November 20, 2015.

2 Henderson BE, Ross R \& Bernstein L. Estrogens as a cause of human cancer: the Richard and Hinda Rosenthal Foundation award lecture. Cancer Research 198848 246-253.

3 Dinda S, Sanchez A \& Moudgil V. Estrogen-like effects of thyroid hormone on the regulation of tumor suppressor proteins, p53 and retinoblastoma, in breast cancer cells. Oncogene 200221 761-768. (doi:10.1038/sj.onc.1205136)

4 Nogueira CR \& Brentani MM. Triiodothyronine mimics the effects of estrogen in breast cancer cell lines. Journal of Steroid Biochemical Molecular Biology 199659 271-279. (doi:10.1016/S09600760(96)00117-3)

5 Conde I, Paniagua R, Zamora J, Blánquez MJ, Fraile B, Ruiz A \& Arenas MI. Influence of thyroid hormone receptors on breast cancer cell proliferation. Annals of Oncology 200617 60-64. (doi:10.1093/annonc/ mdj040)

6 Hall LC, Salazar EP, Kane SR \& Liu N. Effects of thyroid hormones on human breast cancer cell proliferation. Journal of Steroid Biochemical Molecular Biology 2008109 57-66. (doi:10.1016/j.jsbmb.2007.12.008)

7 Davis PJ, Leonard JL \& Davis FB. Mechanisms of nongenomic actions of thyroid hormone. Frontiers in Neuroendocrinology 200829 211-218. (doi:10.1016/j.yfrne.2007.09.003)

8 Smyth PP. The thyroid and breast cancer: a significant association? Annals of Medicine 199729 189-191. (doi:10.3109/ 07853899708999335)

9 Kuijpens JLP, Nyklíctek I, Louwman MWJ, Weetman TAP, Pop VJM \& Coebergh J-WW. Hypothyroidism might be related to breast cancer in post-menopausal women. Thyroid 200515 1253-1259. (doi:10.1089/ thy.2005.15.1253)

10 Szychta P, Szychta W, Gesing A \& Lewi A. TSH receptor antibodies have predictive value for breast cancer - retrospective analysis. Thyroid Research 20136 8. (doi:10.1186/1756-6614-6-8)

11 Hellevik AI, Asvold BO, Bjøro T, Romundstad PR, Nilsen TIL \& Vatten LJ. Thyroid function and cancer risk: a prospective population study. Cancer Epidemiology, Biomarkers and Prevention 200918 570-574. (doi:10.1158/1055-9965.EPI-08-0911)

12 Tosovic A, Bondeson A-G, Bondeson L, Ericsson U-B, Malm J \& Manjer J. Prospectively measured triiodothyronine levels are positively associated with breast cancer risk in postmenopausal women. Breast Cancer Research 201012 R33. (doi:10.1186/bcr2587)

13 Smyth PP, Smith DF, McDermott EW, Murray MJ, Geraghty JG \& O'Higgins NJ. A direct relationship between thyroid enlargement and 
breast cancer. Journal of Clinical Endocrinology and Metabolism $1996 \mathbf{8 1}$ 937-941. (doi:10.1210/jcem.81.3.8772554)

14 Turken O, NarIn Y, DemIrbas S, Onde ME, Sayan O, KandemIr EG, YaylacI M \& Ozturk A. Breast cancer in association with thyroid disorders. Breast Cancer Research 20035 R110-R113. (doi:10.1186/ bcr609)

15 Tosovic A, Becker C, Bondeson AG, Bondeson L, Ericsson UB, Malm J \& Manjer J. Prospectively measured thyroid hormones and thyroid peroxidase antibodies in relation to breast cancer risk. International Journal of Cancer 20122133 2126-2133. (doi:10.1002/ijc.27470)

16 Weiss HA, Brinton LA, Potischman NA, Brogan D \& Coates RJ. Breast cancer risk in young women and history of selected medical conditions. International Journal of Epidemiology 199928 816-823. (doi:10.1093/ije/ 28.5.816)

17 Simon MS, Tang M-TC, Bernstein L, Norman SA, Weiss L, Burkman RT, Daling JR, Deapen D, Folger SG, Malone K et al. Do thyroid disorders increase the risk of breast cancer? Cancer Epidemiology, Biomarkers and Prevention 200211 1574-1578.

18 Angelousi AG, Anagnostou VK, Stamatakos MK, Georgiopoulos GA \& Kontzoglou KC. Mechanisms in endocrinology: primary HT and risk for breast cancer: a systematic review and meta-analysis. European Journal of Endocrinology 2012166 373-381. (doi:10.1530/EJE-11-0838)

19 Huang J, Jin L, Ji G, Xing L, Xu C, Xiong X, Li H, Wu K, Ren G \& Kong L. Implication from thyroid function decreasing during chemotherapy in breast cancer patients: chemosensitization role of triiodothyronine. BMC Cancer 201313 334. (doi:10.1186/1471-2407-13-334)

20 Pedersen CB. The Danish Civil Registration System. Scandinavian Journal of Public Health 201139 22-25. (doi:10.1177/ 1403494810387965)

21 Lynge E, Sandegaard JL \& Rebolj M. The Danish National Patient Register. Scandinavian Journal of Public Health 201139 30-33. (doi:10.1177/1403494811401482)

22 Schmidt M, Schmidt S, Sandegaard J, Eherenstein V, Pedersen L \& Sørensen HT. The Danish National Patient Registry: a review of content, data quality, and research potential. Clinical Epidemiology 2015 7 449-490. (doi:10.2147/CLEP.S91125)

23 Gjerstorff ML. The Danish Cancer Registry. Scandinavian Journal of Public Health 201139 42-45. (doi:10.1177/1403494810393562)

24 Bjerregaard B \& Larsen OB. The Danish Pathology Register. Scandinavian Journal of Public Health 201139 72-74. (doi:10.1177/ 1403494810393563)

25 Charlson ME, Pompei P, Ales KL \& MacKenzie CR. A new method of classifying prognostic comorbidity in longitudinal studies: development and validation. Journal of Chronic Diseases 198740 373-383. (doi:10.1016/0021-9681(87)90171-8)

26 Breslow NE \& Day NE. Statistical methods in cancer research, Volume II-The design and analysis of cohort studies. IARC Scientific Publications 198782 1-406.

27 Metso S, Auvinen A, Huhtala H, Salmi J, Oksala H \& Jaatinen P. Increased cancer incidence after radioiodine treatment for hyperthyroidism. Cancer 2007109 1972-1979. (doi:10.1002/cncr.22635)

28 Holm IA, Manson JE, Michels KB, Alexander EK, Willett WC \& Utiger RD. Smoking and other lifestyle factors and the risk of Graves' hyperthyroidism. Archives of Internal Medicine 2005165 1606-1611. (doi:10.1001/archinte.165.14.1606)

29 Cristofanilli M, Yamamura Y, Kau S, Bevers T, Strom S, Patangan M, Hsu L, Krishnamurthy S, Theriault RL \& Hortobagyi GN. Thyroid hormone and breast carcinoma. Primary hypothyroidism is associated with a reduced incidence of primary breast carcinoma. Cancer 2005103 1122-1128. (doi:10.1002/cncr.20881)

30 Park JW, Zhao L \& Cheng S. Inhibition of estrogen-dependent tumorigenesis by the thyroid hormone receptor $\beta$ in xenograft models. American Journal of Cancer Research 20133 302-311.

31 Guigon CJ, Kim DW, Willingham MC \& Cheng S-Y. Mutation of thyroid hormone receptor- $\beta$ in mice predisposes to the development of mammary tumors. Oncogene 201130 3381-3390. (doi:10.1038/onc. 2011.50)

32 Shao ZM, Sheikh MS, Rishi AK, Dawson MI, Li XS, Wilber JF, Feng P \& Fontana JA. Thyroid hormone enhancement of estradiol stimulation of breast carcinoma proliferation. Experimental Cell Research 1995218 1-8. (doi:10.1006/excr.1995.1124)

33 Vestergaard P \& Mosekilde L. Fractures in patients with hyperthyroidism and hypothyroidism: a nationwide follow-up study in 16,249 patients. Thyroid 200212 411-419. (doi:10.1089/105072502760043503)

34 Erichsen R, Lash TL, Hamilton-Dutoit SJ, Bjerregaard B, Vyberg M \& Pedersen L. Existing data sources for clinical epidemiology: The Danish National Pathology Registry and Data Bank. Clinical Epidemiology 2010 2 51-56. (doi:10.2147/CLEP.S9908)

35 Storm HH, Michelsen EV, Clemmensen IH \& Pihl J. The Danish Cancer Registry-history, content, quality and use. Danish Medical Bulletin 1997 44 535-539.

36 Laurberg P, Jørgensen T, Perrild H, Ovesen L, Knudsen N, Pedersen IB, Rasmussen LB, Carlé A \& Vejbjerg P. The Danish investigation on iodine intake and thyroid disease, DanThyr: status and perspectives. European Journal of Endocrinology 2006155 219-228. (doi:10.1530/eje.1. 02210)

37 Leese GP \& Jung RT. Increasing prevalence and incidence of thyroid disease in Tayside, Scotland: the Thyroid Epidemiology Audit and Research Study (TEARS). Clinical Endocrinology 200868 311-316. (doi:10.1111/j.1365-2265.2007.03051.x)

38 Vaidya B \& Pearce SHS. Diagnosis and management of thyrotoxicosis. BMJ 2014349 g5128. (doi:10.1136/bmj.g5128)

39 Carlé A, Bülow Pedersen I, Knudsen N, Perrild H, Ovesen L, Rasmussen LB, Jørgensen T \& Laurberg P. Graves' hyperthyroidism and moderate alcohol consumption: evidence for disease prevention. Clinical Endocrinology 201379 111-119. (doi:10.1111/cen.12106)

40 Van den Brandt PA, Spiegelman D, Yaun SS, Adami HO, Beeson L, Folsom AR, Fraser G, Goldbohm RA, Graham S, Kushi L et al. Pooled analysis of prospective cohort studies on height, weight, and breast cancer risk. American Journal of Epidemiology 2000152 514-527. (doi:10.1093/aje/152.6.514)

41 Cook NR, Rosner BA, Hankinson SE \& Colditz GA. Mammographic screening and risk factors for breast cancer. American Journal of Epidemiology 2009170 1422-1432. (doi:10.1093/aje/kwp304)
Received 6 October 2015

Revised version received 23 November 2015

Accepted 19 January 2016 